\title{
Preliminary investigation into the cause of acid mine water induced seismicity in Johannesburg
}

Izak du Plessis ${ }^{1}$, Keagen Liebenberg ${ }^{1}$, Ansie Smit ${ }^{2}$, Serena Coetzee ${ }^{1}$ and Andrzej Kijko ${ }^{2}$

${ }^{1}$ Centre for Geoinformation Science, Department of Geography, Geoinformatics and Meteorology, University of

Pretoria, South Africa, serena.coetzee@up.ac.za

${ }^{2}$ UP Natural Hazard Centre Africa, University of Pretoria, South Africa

DOI: http://dx.doi.org/10.4314/sajg.v4i3.10

\section{Abstract}

A preliminary investigation was done into the possible causes of the increased seismic activity in the Witwatersrand Basin. The paper focuses on approximated underground mining areas, groundwater mobility, rock types and the proximity of fault lines to seismic events. These parameters were mapped and correlated with observed seismicity in the area. There is some indication that the presence of underground mining areas has a positive relationship with the occurrence of seismic events. The other parameters exhibit a negative relationship with seismic activity. However, more detailed investigations are required before final conclusions can be drawn. An approach to risk assessment of possible earthquake scenarios in the City of Johannesburg (CoJ) is proposed. The approach aims to assess potential damage to infrastructure and loss of life in the case of an earthquake. The results of such an assessment may provide justification for more detailed investigations.

\section{Introduction}

South Africa is a low seismic activity zone, with most of the natural seismicity activity occurring in the Western Cape and northern parts of KwaZulu-Natal. Natural seismic events are caused by faults in the Earth's crust, whereby the stress and pressure are built up in the fault and then released as a seismic event. However, the majority of South Africa's seismic events are found in the North West, Gauteng and Free State provinces and are attributed to deep-level mining for gold and platinum. This can be seen on the seismic hazard map of South Africa in Figure 1. Such seismic activity caused by human activity in a specific region is known as induced seismicity (Gibowicz and Kijko, 1994). The focus of this paper is on the seismicity observed after the closure of mines in the Witwatersrand Basin.

Once a mine is closed, all associated operations of extracting mine water from the underground voids are also terminated. As a result, the underground mine voids are flooded, causing an increase in underground pressure. In addition, chemical and geochemical reactions between the mine rock strata, mine wastes and oxygen cause the water in underground mine voids to become acidic. The quantity, strength and impact of acid mine drainage depends on the amount and rate of oxidation of sulphides embedded in the rock's mineral composition. Factors such as the amount of water passing over or through the rock material also have a significant effect on the rate of acid generation (Birch, 2013). The corrosive nature of the acid mine drainage, unlike uncontaminated water, lubricates the fractures and faults. High underground water pressures coupled with the lubrication of faults reduce clamping forces, causing them to slip. This may affect the stability of artificial and natural fractures and generate seismic events (Durrheim et al., 2006; Goldbach 2010).

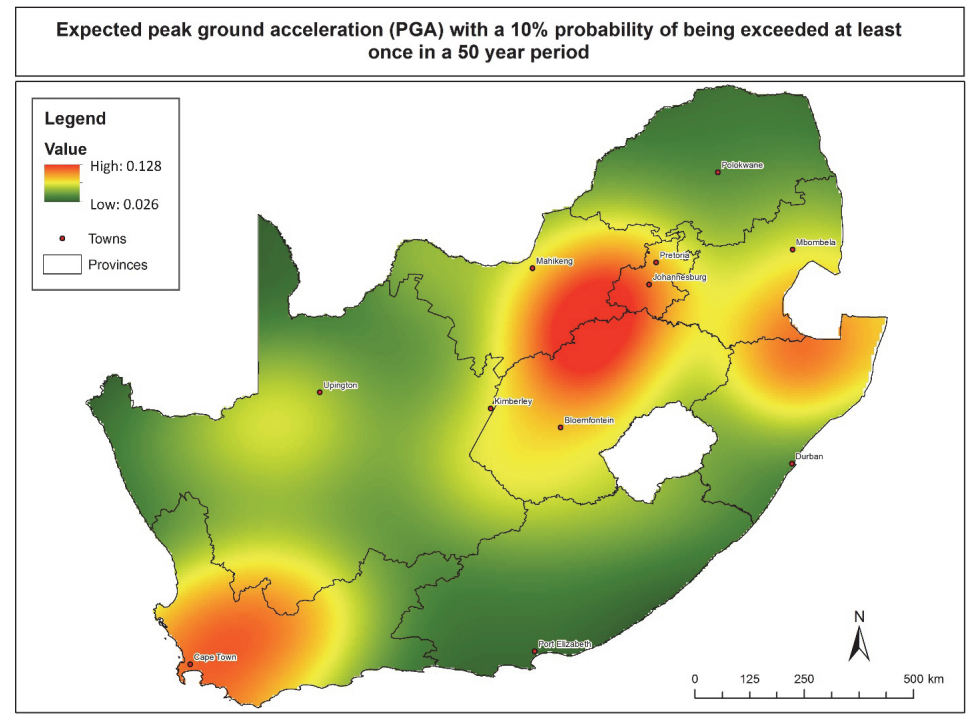

Figure 1. Seismic hazard map of South Africa representing the expected peak ground acceleration (g) with a $10 \%$ probability of being exceeded in a 50-year period (Source: Esterhuyse et al. 2014) 
Even though mining operations have significantly decreased in the Witwatersrand area, seismic events up to local magnitude $\left(M_{L}\right) 5.3$ have been recorded (Coetzee et al., 2010). In 2010, a team of experts for the Department of Water Affairs conducted a study on mine water management in the Witwatersrand goldfields, with special emphasis on acid mine drainage. They reported that the average number of monthly seismic events had increased from 5.9 to 11.7 after pumping from underground mine voids had stopped (Coetzee et al. 2010). Kijko et al. (2012) also showed a significant increase in energy released by seismic events between 2000 and 2010, as seen in Figure 2. The increase in seismicity has sparked concerns among the general population in the affected region, in disaster management centres and in the insurance and reinsurance industry. Fundamental questions include if more seismic events with larger and potential damaging magnitudes can be expected in future and what the foreseeable worst-case scenario would be.

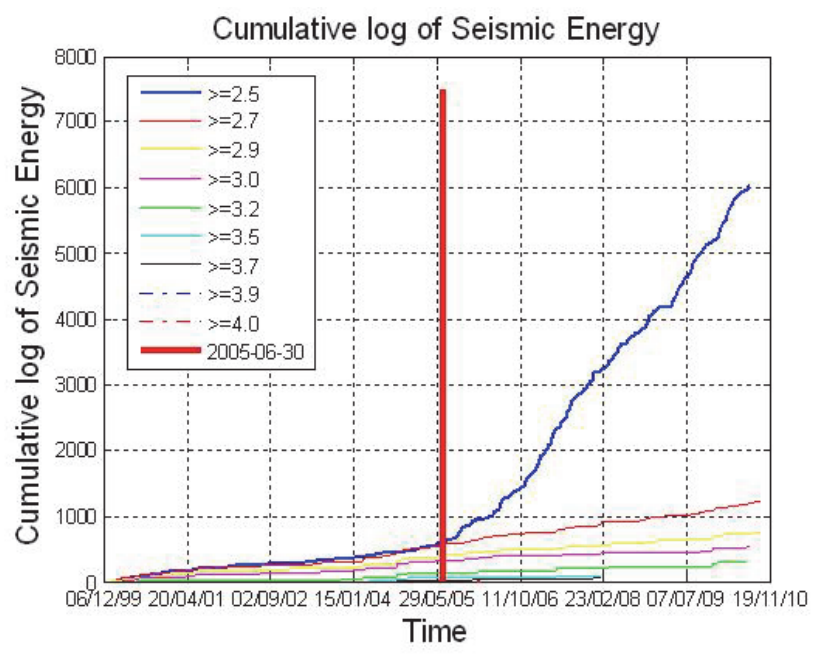

Figure 2. Sum of the log of seismic energy released in Johannesburg area by seismic events with $\mathrm{M}_{\mathrm{L}}$ magnitudes 2.5 and stronger during the period 2000/01/01 - 2010/12/31 (Source: Kijko et al. 2012)

In an attempt to answer some of these questions, it was decided to investigate which parameters are potentially aiding acid mine water (AMW) to trigger more seismic events. Geoinformation tools were used in the investigation due to their capability to combine different spatial datasets for analysis purposes. A weighted overlay procedure was used to explore possible causes for the increase in seismic activity in the Witwatersrand. A better visualization and understanding of the underlying causes can assist government and decision-makers in developing action plans to halt and possibly reverse this worrying phenomenon. Section 2 describes the preliminary investigation into the possible causes of the increased seismic activity in the Witwatersrand Basin; section 3 proposes an approach to risk assessment of possible earthquake scenarios in the City of Johannesburg (CoJ); and a conclusion is provided in section 4.

\section{Spatial analysis of AMW parameters and seismicity}

\subsection{Research design}

The study area for the investigation was a minimum bounding box around the seismic events that occurred during 2000 and 2013 in the Witwatersrand Basin in South Africa (Figure 3). Seismic event data was made available by the Council for Geoscience and the University of Pretoria Natural Hazard Centre. Events from 2000 onwards were included, as we were only interested in seismic events after mining activities had decreased.

Drawing on a review of literature, the following parameters with the potential to influence AMW-induced seismic events were identified: underground mine voids, rock types, groundwater mobility, proximity to fault lines, rainfall patterns, underground water extraction periods and underground water levels (Bos, 1994; Cappa, 2009; Gough, 1970; Simpson et al., 1988; Talwani 1997). Due to data availability to the authors, the first four parameters were included in this investigation. For this paper, it is assumed that only these parameters influence AMW-induced seismic events.

A weighted overlay procedure was used to identify areas where multiple conditions for an AMW-induced seismic event exist. This procedure allows the integrated analysis of different spatial datasets (such as those available for this investigation, see 2.2) by applying a common scale of values to diverse and dissimilar input data. Each of the spatial parameter datasets was converted to a cell based raster file. A $30 \mathrm{~m}$ cell size was chosen to optimize processing speed without compromising too much detail. Input datasets were reclassified to a common scale and five combinations of different weightings for each parameter were used in the procedure. The result of each combination was compared to a kernel density model of seismic events. 


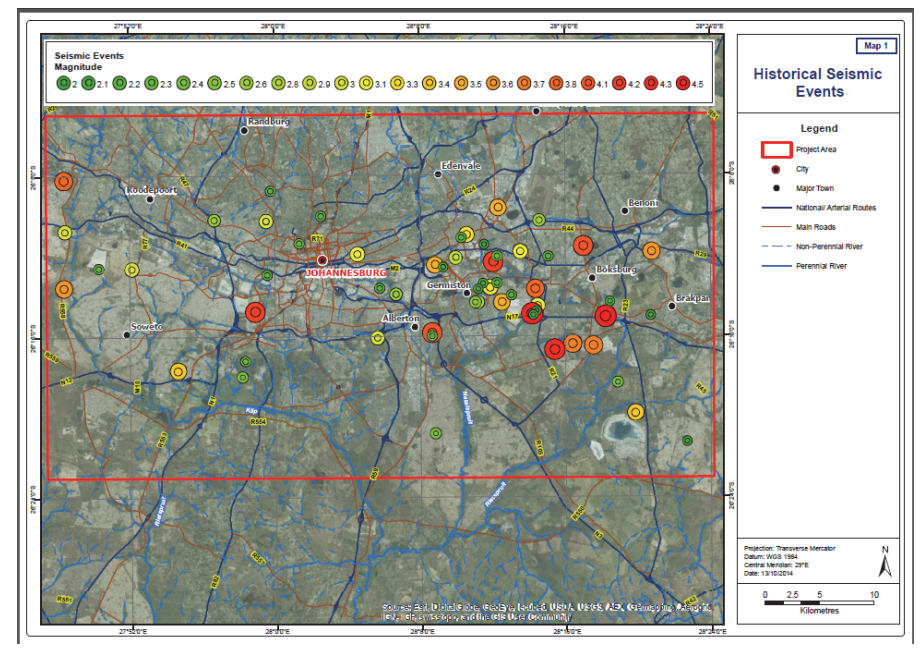

Figure 3. Study area for the spatial analysis of AMW conditions

\subsection{Data preparation}

\subsubsection{Seismic event catalogue}

The seismic event catalogue used in this investigation consists of a subset (2000-2013) of the Council of Geoscience national catalogue, together with an event set from the University of Pretoria Natural Hazard Centre for events between 1996 and 2010. The merged dataset was reduced by excluding events outside the Witwatersrand Basin, as well as events smaller than magnitude 2 which occurred during the active mining period in the Witwatersrand Basin, i.e. prior to 2000. Events of magnitude 2 and smaller were removed from this investigation, as they are most likely attributable to residual mining stresses. The final catalogue consisted of 61 events.

\subsubsection{Underground mine voids}

The spatial distribution and interconnectivity of the mine voids in the study area was approximated from the locations of mine waste dumps and shafts (points) obtained from DRDGOLD Limited (www.drd.co.za). Based on the assumption that material is rarely removed more than $1 \mathrm{~km}$ away from a shaft location (Greg Ovens, Ergo Mining, personal communication), a buffer of $1 \mathrm{~km}$ around the waste dump was chosen to approximate the area of underground mine voids. This resulted in an interconnected network of approximated underground mine voids (Figure 4). Approximation was necessary because the plans with the exact size and shape for these voids are the property of the associated mining companies and not available to the general public.

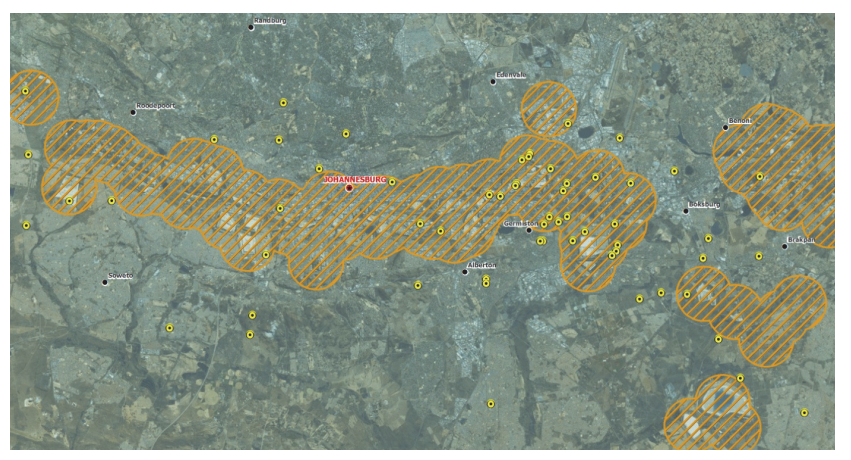

Figure 4. Approximation of underground mine voids in the study area

\subsubsection{Rock type}

A detailed dataset containing the distribution of rock types in the Witwatersrand area was obtained from Digby Wells Environmental. This dataset contained polygons representing different rock types classified as sedimentary, igneous or metamorphic.

\subsubsection{Groundwater mobility}

This dataset comprises polygons representing the ground water mobility in terms of three types of material structures found in the study area, namely: intergranular, fractured and karst (Figure 5). The dataset was obtained from Digby Wells Environmental. 


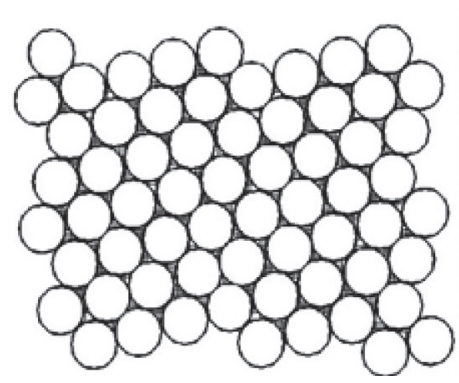

a) Intergranular

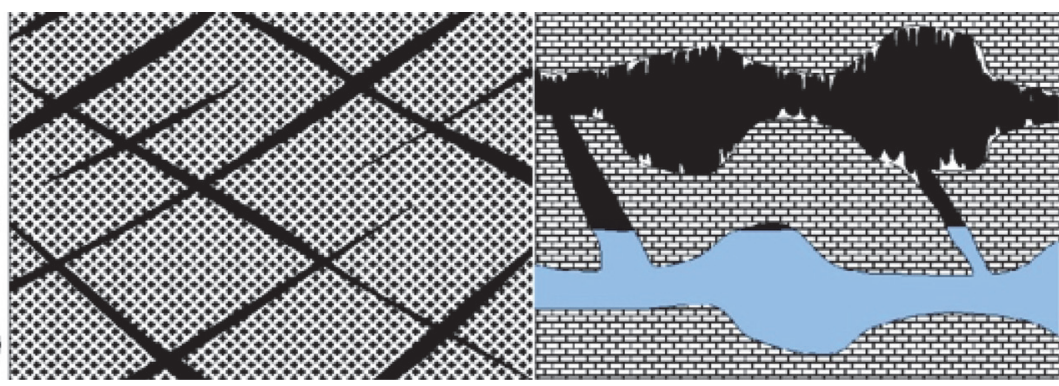

b) Fractured

c) Karst

Figure 5. Material structures found in the Witwatersrand (Source: Bos 1994)

The material structures differ in the way groundwater moves through them. Formations chemically weathered by solutions can facilitate the forming of cavernous structures, usually when acid solutions come into contact with rock types such as limestone and dolomite (Bos, 1994). Each material structure was further subdivided into classes of groundwater mobility representing the number of litres per second $(l / s)$ that move through it (Table 1$)$.

\subsubsection{Fault line proximity}

The fault lines included in the 1:50,000 topographic dataset of National Geo-Spatial Information (Department Rural Development and Land Reform) were converted from lines to polygons by creating five rings at intervals of $1 \mathrm{~km}$ around each fault line.

\subsection{Results}

Table 1 provides a detailed description of the reclassification of the parameters to a standardized scale for the weighted overlay procedure. The scale ranges from least suitable/susceptible (1) to most suitable/susceptible (9) to induce seismic activity. Presence of an underground mine void was rated with a nine, everything else as a one. Higher ground water mobility $(l / s)$ was rated closer to nine. Based on a literature review on the susceptibility of different rock types to acid water weathering, the identified rock types were rated from least susceptible (1) to most susceptible (9) to acid water weathering. The proximity to fault lines was classified in discrete distances of $1 \mathrm{~km}$, i.e. fault lines at distance of $1.01 \mathrm{~km}$ and $1.99 \mathrm{~km}$ from an event were both rated as eight. The classification considers proximity to fault lines within $5 \mathrm{~km}$; anything beyond that was classified as a one to account for uncertainty in location estimation of seismic events in the catalogue.

The results of the weighting overlay procedure for the five combinations of weightings can be seen in Table 2 . In Results 1 to 4, one of the parameters has an increased weight of $40 \%$ compared to $20 \%$ assigned to the other three. In Result 5 the parameters are equally weighted at $25 \%$.

Table 1. Reclassification of parameters to a standardized scale

\begin{tabular}{|c|c|c|c|c|c|c|c|}
\hline \multicolumn{2}{|c|}{ Underground mine voids } & \multicolumn{2}{|c|}{ Groundwater mobility } & \multicolumn{2}{|c|}{ Rock type } & \multicolumn{2}{|c|}{ Fault line proximity } \\
\hline Present & 9 & Karst $>5.01 / \mathrm{s}$ & 9 & Dolomite & 9 & $1 \mathrm{~km}$ & 9 \\
\hline Not present & 1 & Fractured $>5.01 / \mathrm{s}$ & 9 & Sandstone & 6 & $2 \mathrm{~km}$ & 8 \\
\hline & & Karst $2.0-5.01 / \mathrm{s}$ & 8 & Shale & 6 & $3 \mathrm{~km}$ & 7 \\
\hline & & Fractured $2.0-5.01 / \mathrm{s}$ & 8 & Diamictite & 6 & $4 \mathrm{~km}$ & 6 \\
\hline & & Intergranular 2.0-5.0 1/s & 8 & Migmatite & 4 & $5 \mathrm{~km}$ & 5 \\
\hline & & Fractured $0.5-2.01 / \mathrm{s}$ & 7 & Granodiorite & 4 & $>5 \mathrm{~km}$ & 1 \\
\hline & & Intergranular $0.5-2.01 / \mathrm{s}$ & 7 & Syenite & 3 & & \\
\hline & & Intergranular $0.0-0.5 \mathrm{l} / \mathrm{s}$ & 6 & Granite & 3 & & \\
\hline & & & & Basalt & 3 & & \\
\hline & & & & Dolerite & 3 & & \\
\hline
\end{tabular}




\begin{tabular}{|l|l|l|l|l|l|}
\hline \multirow{2}{*}{} & & & Quartzite & 2 & \\
\cline { 2 - 5 } & & & Alluvium & 1 & \\
\hline
\end{tabular}

Next, the correlation between each of the five weighted overlay results and the kernel density model of the locations of observed seismic events was established with the use of the Band Collections Statistics Toolbox of ArcGIS. This provides an estimation of the correlation among the combinations of the influence of underground mine voids, rock types, groundwater mobility and fault line proximity, and the observed seismicity (Table 3). A higher correlation indicates that a specific combination of parameters has a bigger impact or plays a bigger role in triggering seismic events in the Witwatersrand Basin.

A positive correlation was found between Result 1 and the observed seismic events. This indicates that underground mine voids, likely to be filled with AMW, are a potential contributory factor to the occurrence of seismic activity in the study area. The very small correlation obtained for Result 2 indicates that groundwater mobility plays a negligible role in the occurrence of seismic events. The negative correlations for Results 3 and 4 suggest that rock type and proximity to faults lines may not play a role in inducing seismic activity, but could possibly prohibit it.

Table 2. Weighted overlay results

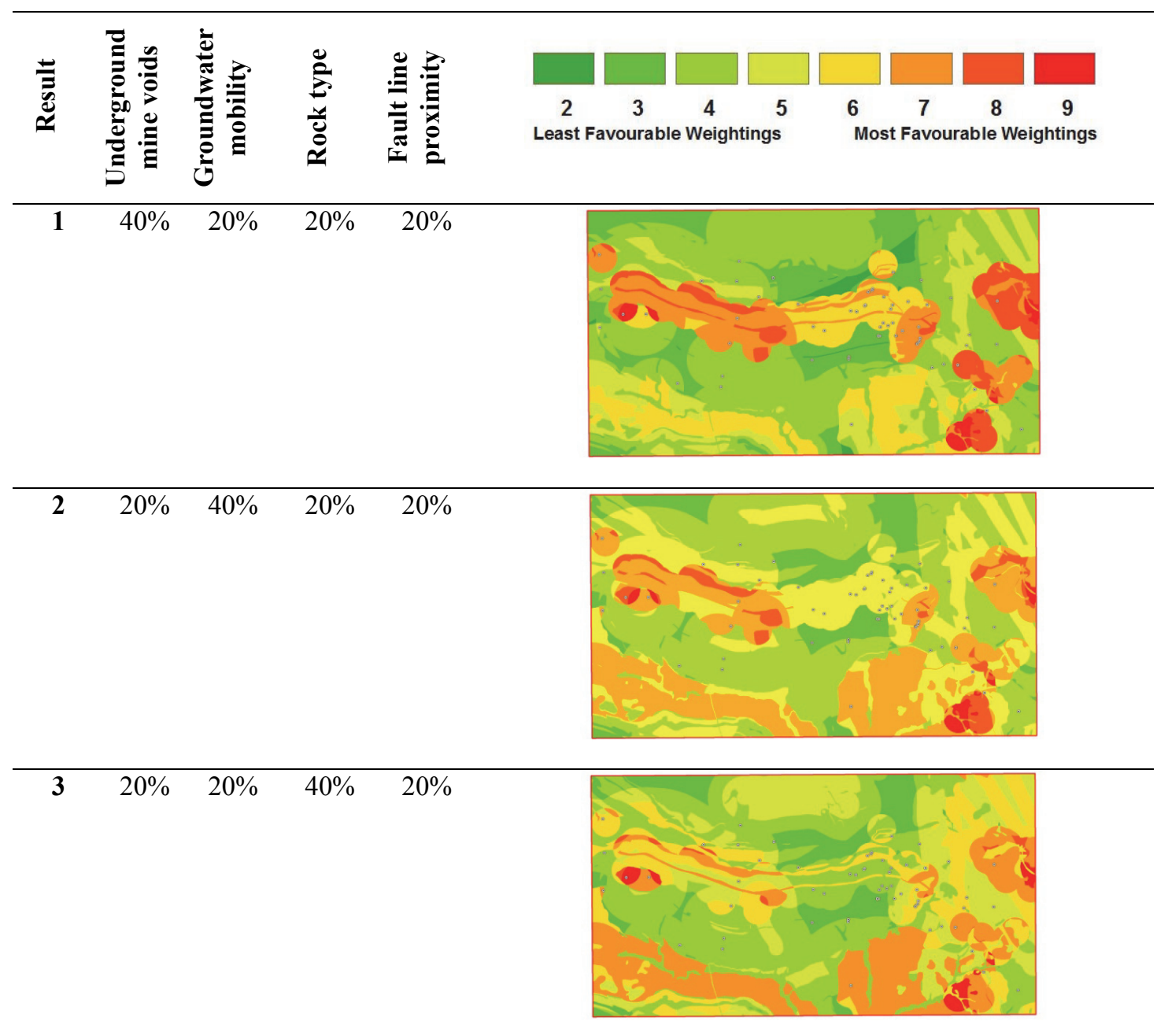

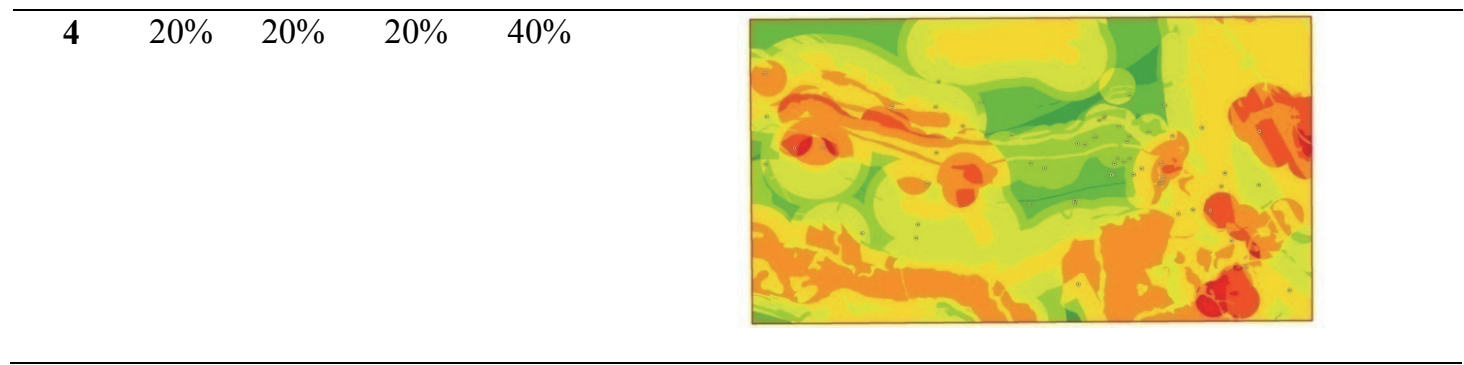




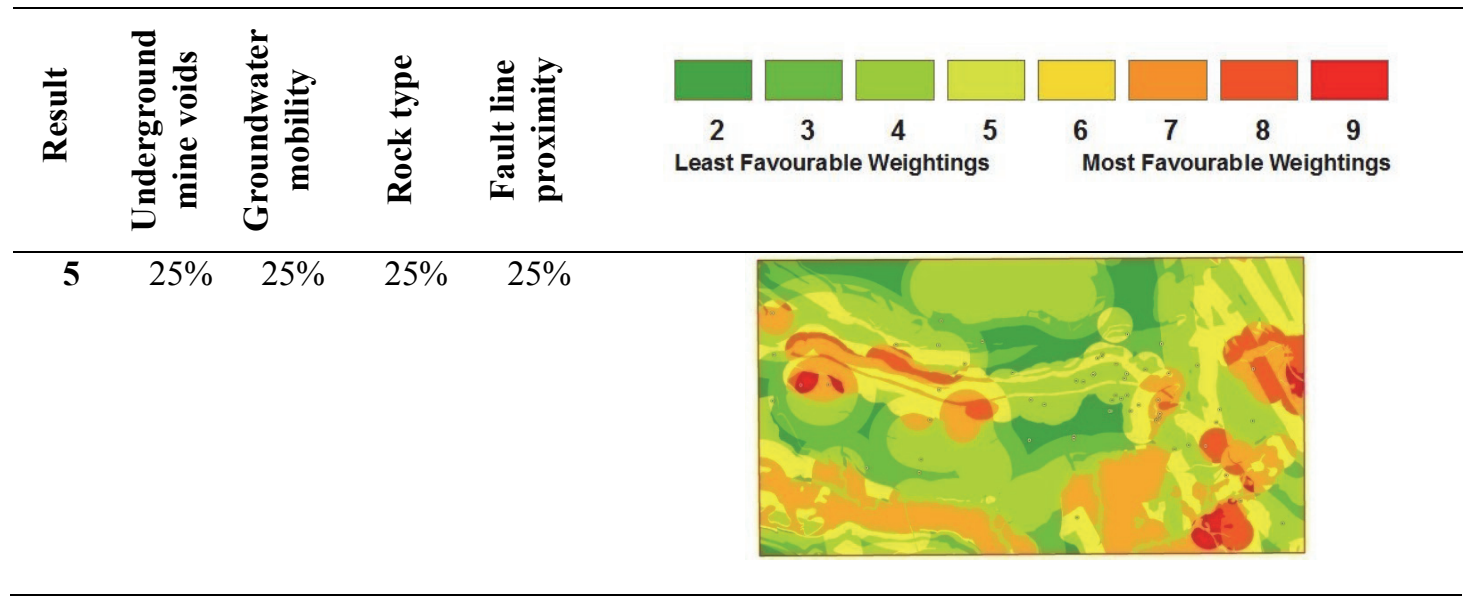

The correlation between the occurrence of seismic events and the case where we assume equal weighting is very small. The four parameters, equally weighted, appear not to have an effect on the seismic activity in the study area. All the obtained correlations are small and at best indicate a potential negative or positive relationship between the parameters. The applied Band Collections Statistics Toolbox unfortunately does not provide the associated significance results for the calculated correlations.

Table 3. Correlations of the weighted overlay results with observed seismic activity in the Witwatersrand Basin. Result 1 to 5 represent the weighted overlay results of underground mine voids, groundwater mobility, rock type and fault line proximity.

$\%$ Weight per layer Correlation

(underground mine void, groundwater mobility, rock type, fault line proximity)

\begin{tabular}{llc}
\hline Result 1 & $(40 \%, 20 \%, 20 \%, 20 \%)$ & 0.15272 \\
\hline Result 2 & $(20 \%, 40 \%, 20 \%, 20 \%)$ & -0.00911 \\
\hline Result 3 & $(20 \%, 20 \%, 40 \%, 20 \%)$ & -0.1064 \\
\hline Result 4 & $(20 \%, 20 \%, 20 \%, 40 \%)$ & -0.15825 \\
\hline Result 5 & $(25 \%, 25 \%, 25 \%, 25 \%)$ & -0.04321 \\
\hline
\end{tabular}

\subsection{Discussion of results}

In this preliminary investigation, the spatial correlation between four parameters (underground mine voids, rock types, groundwater mobility, proximity to fault lines) and the locations of seismic events was analysed. The correlations obtained for Results 1 to 5 are too small to indicate the strength of possible relationships with seismic activity. It can, however, be suggested that a potential positive relationship exists between seismic activity and the presence of underground mine voids. Potential negative relationships are exhibited between seismic activity and rock type, as well as between seismic activity and fault line proximity.

It can be concluded that the underground mine voids in the Witwatersrand Basin could possibly be a contributory parameter for induced seismic activity, while rock type seems to be an inhibiting factor. However, since each weighted combination included all four of the parameters, the impact of each parameter on its own cannot safely be determined. Future research should include the correlation of each individual parameter with seismic activity separately, as well as the correlation between the parameters themselves. Another aspect to consider is the uncertainty associated with the assigned locations of seismic events. It is safe to assume that due to a sparsely populated national seismic network, location errors from a few hundred meters to $5 \mathrm{~km}$ can be expected in the seismic event catalogue. This may have influenced the correlation results. Unfortunately, the significance of each of the developed correlations was not provided with the applied ArcGIS Band Collections Statistical Tool.

Data, time and cost constraints, as well as the assumptions and approximations, had an impact on the results. Firstly, the exact size and shape of underground mine voids was approximated as concentric circles around mine waste dumps and shafts. Secondly, the parameters were reclassified to a standardized scale from one to nine for the weighted overlay 
procedure. In future, we plan to explore alternative spatial analysis techniques that consider the actual (non-discrete) values.

The study may also be repeated with a more detailed and updated seismic event catalogue, which exists, but is not yet available to the public. Additional parameters that could impact the effect of AMW on seismic activity will be included as the data becomes available.

\section{Proposed approach to seismic risk assessment}

Currently high levels of seismic activity are observed in the Germiston area, with a high concentration of events observed to the eastern part of the town, as seen in Figure 6. Due to speculation that AMW may be the cause of the increased levels of seismicity, an assessment of the potential risk associated with these increased seismic activity levels is needed. Results of such an assessment may provide justification for more detailed investigations into the cause of the increased seismic activity.

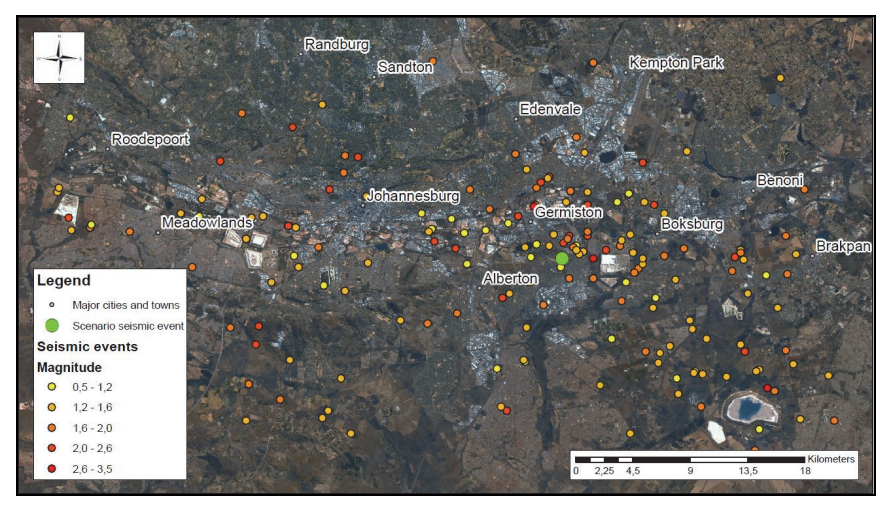

Figure 6: Map of the seismic activity in the Johannesburg region for the time period 2011 to 2014.

Seismic risk is defined as the probability of losses occurring due to a seismic event and can be defined as multiplying seismic hazard with vulnerability and the amount of potential losses (van Westen, 2013). Seismic hazard is defined as the probability of an earthquake occurring in a given geographic area and seismic vulnerability refers to the correlation of loss (e.g. to buildings) and casualties with a hazard's intensity. The remainder of this section details a proposed approach to assess seismic risk in CoJ through a hazard, vulnerability and potential loss analysis. An assessment based on this approach is currently underway.

Seismic hazard and risk analyses can be done in a deterministic or a probabilistic way (Davies and Kijko, 2003). Deterministic methods use earthquake scenarios to determine the hazard and risk, while probabilistic approaches calculate the probability of seismic hazard and risk levels that can be expected to occur within a specified time period (Yuan, 2003). The deterministic approach was chosen for the seismic risk assessment in CoJ, as it is easier to implement and is more flexible with regards to handling changes in data (Mualchin, 2011). The assessment investigates the impact of different possible scenario earthquakes on people and buildings in CoJ.

As a first step in the proposed approach, an area currently experiencing high levels of seismic activity in the vicinity of CoJ was determined. The seismic event catalogue used in the analysis consists of the most recent events in CoJ (2011-2014) and was provided by the Council for Geosciences (Figure 6).

Next, hazard is determined by modelling attenuation for scenario earthquakes of various magnitudes. From investigations of similar geological areas around the world, the expected maximum magnitude of a tectonic-origin seismic event in Gauteng could be in the order of 6.8 (Fenton et al., 2006). However, most seismic hazard models in South Africa, without taking the potential effects of acid mine water into consideration, estimate an expected maximum magnitude of 5.5 for the Gauteng region due to normal mining activities (Davies and Kijko, 2003). To explain the proposed approach, the impact of a hypothetical seismic event of magnitude M6.0 in the seismic active, eastern part of Germiston is described. The considered epicentre (location) of the scenario event is presented as a green dot in Figure 6. Additional scenarios are being considered in the assessment that is currently underway. The epicentre and magnitude of the scenario event were chosen to account for the potential effects of AMW.

The relationship between the ground motion due to a seismic event and the damage observed can be described through Modified Mercalli (MM) Intensity scale (Wood and Neumann, 1931, Sieberg, 1923). The MM Intensity scale describes damages ranging from 'nothing felt but animals were disturbed' (intensity level I) to 'total destruction of buildings and severe geological disturbances' (intensity level XII). 
Equation [1] is used to calculate the intensity of the earthquake at its epicentre $I_{0}$, with $m$ the magnitude of the earthquake and $b_{1}$ and $b_{2}$ constants. Equation [2] is used to calculate the intensity at a certain distance from the epicentre [I(@site)], with $r$ the distance from the earthquake's epicentre and $a_{1}$ to $a_{3}$ constants (Lay and Wallace, 1995). The distances for intensity values at 1/2 MM (Modified Mercalli) intensity intervals are then solved for and added to a multiple ring buffer.

$$
\begin{aligned}
& I_{0}=\left(b_{1} \times m\right)+b_{2} \\
& I(@ \text { site })=I_{0}+a_{1}+a_{2} \log r+a_{3} r
\end{aligned}
$$

Figure 7 depicts the potential attenuation of the MM intensity from the epicentre of the proposed scenario earthquake of magnitude 6.0 in the Witwatersrand Basin. The predicted intensities from the scenario earthquake in the investigated area were all larger than V on the MM Intensity scale. An event of V MM intensity can cause dishes and glass to break. In some areas of CoJ MM intensities of VII and 1/2 and upward are predicted. Such intensities are classified as very strong, causing poorly built structures to be destroyed. These estimated intensities indicate that even a magnitude 6.0 seismic event at a considerable distance from the study area, can cause significant damage in CoJ.

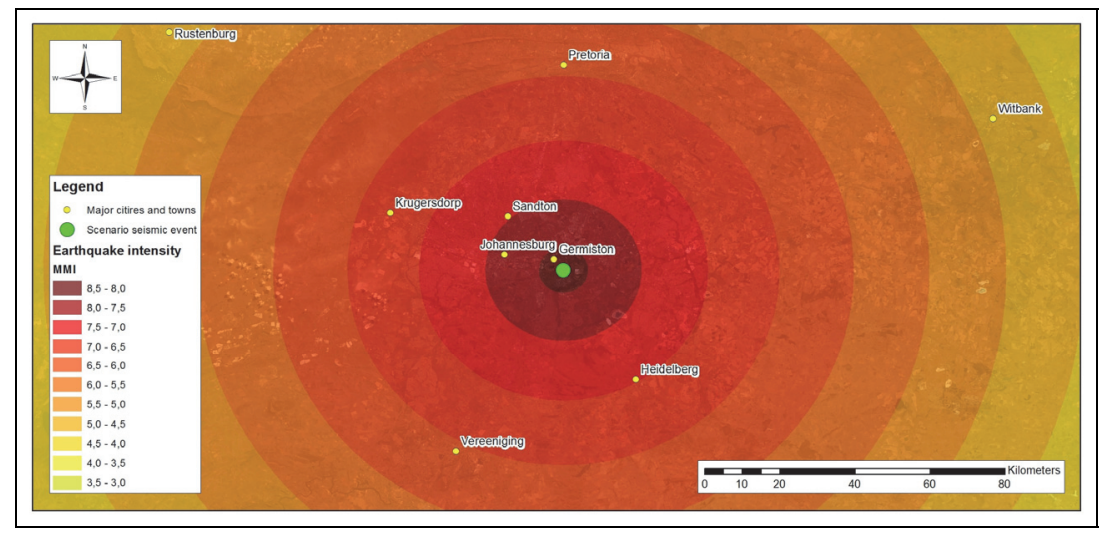

Figure 7. Intensity map showing the attenuation from the epicentre of the MM intensity VI scenario earthquake

A comprehensive risk assessment for a region not only looks at the potential risk to infrastructure, but also to the potential risk of lives that could be lost. In the assessment currently underway, the framework for the vulnerability assessment of people and buildings was taken from Servi (2004).

The study by Servi (2004) focuses on building age, construction material, building condition and number of storeys of the building in the building vulnerability assessment. For CoJ only the construction material and the number of storeys were considered. Building age was not considered to be a major factor in CoJ where buildings are much 'younger' than those in Servi's study area, Turkey (which can be up to 400 years old). Information about the condition of buildings is unfortunately not readily available in South Africa.

Servi (2004) considered the following variables for assessing the vulnerability to people: distance to a hospital for medical help; type of access road for access of emergency personnel; and building vulnerability. It is proposed that the pairwise comparisons in Servi (2004) be modified for the vulnerability analyses of buildings and people in CoJ.

Potential loss is the final variable in the risk equation. For buildings this refers to the direct economic loss of the building in terms of monetary value, based on building valuations available from CoJ. Ideally, the potential loss of people should be the number of people in each building, however such data is not readily available. Instead, daytime population statistics per enumeration area, available from GeoTerraImage, will be used.

The seismic risk can now be calculated by performing a weighted linear combination (WLC) as per Equation [3], where $S R_{i}$ is the seismic risk of a building/people; $H_{i}$ is the intensity value for that building location (seismic hazard); $V_{i}$ is the assigned vulnerability of a building or people; and $P L_{i}$ is the normalised valuation for that building or group of people (potential loss). The resultant multiplication of the three variables is then multiplied by a constant $(10,000)$ to calculate values greater than 1, allowing for easier interpretation. Figures 8 and 9 summarise the proposed approach for assessing seismic risk to buildings and to people.

$$
S R_{i}=H_{i} \times V_{i} \times P L_{i} \times 10000
$$




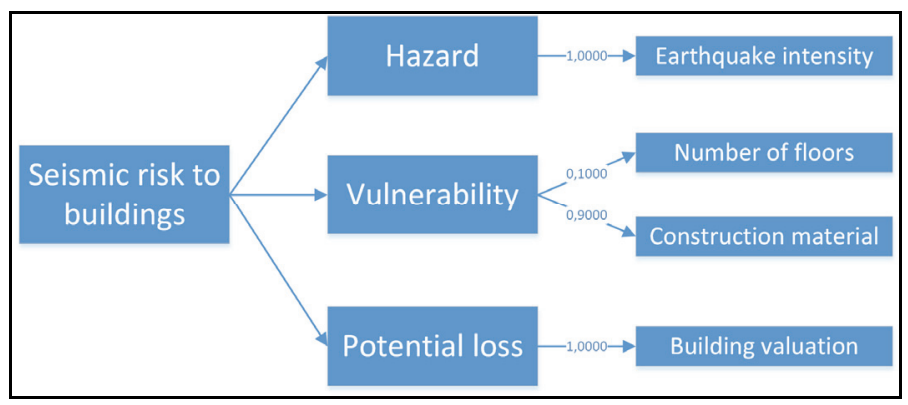

Figure 8. A summary of the procedure to calculate the seismic risk to buildings

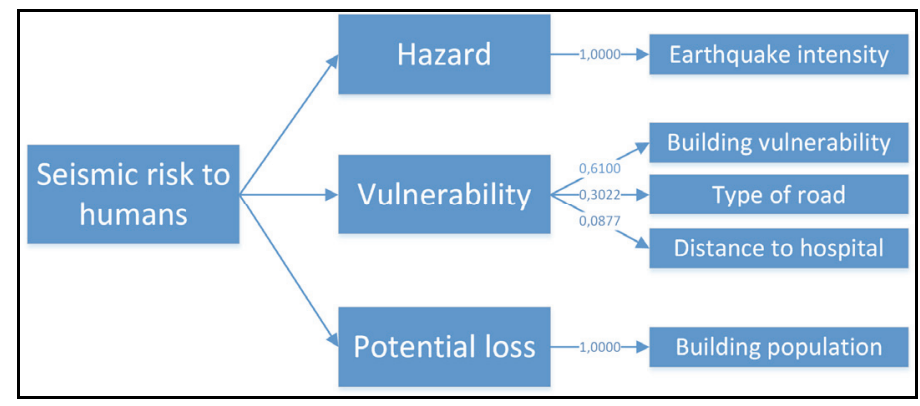

Figure 9. A summary of the procedure to calculate the seismic risk to people

\section{Conclusion}

With the help of geoinformation tools a preliminary investigation was undertaken into the possible causes of increased seismic activity in the Witwatersrand Basin. Data quality and availability, as well as time and cost constraints, impacted the results.

The correlation between the observed seismicity and the weighted layers of the identified parameters (underground mine voids, groundwater mobility, rock type and proximity to fault lines) was determined to assess if these parameters influence the AMW effect on observed seismicity in the study area. From the results it is concluded that the underground mine voids in the Witwatersrand can possibly contribute to the increased induced seismic activity, while rock type seems to be an inhibiting factor. It is expected that the level of groundwater should play a key role in the observed increase of seismicity. Data indicating the level of groundwater over time was not available for this investigation, but should be included in future research. Future research should also indicate if the different calculated correlations are significant.

The results suggest that the presence of acid mine water in the Witwatersrand Basin leads to an increase in seismic activity and subsequently the associated seismic hazard and risk. This indicates that acid mine water should be a concern and more in-depth spatial and temporal statistical analyses are required to accurately identify the relationship between the seismic activity and acid mine water.

An approach to assess the risk of a seismic event to people and buildings in CoJ was proposed in this paper. A seismic risk assessment in CoJ following this approach is currently in progress. Results of such an assessment may provide justification for more detailed investigations into the cause of the increased seismic activity in the Witwatersrand Basin.

The preliminary investigation presented in this paper could be adjusted for more detailed investigations. For example, correlation of individual parameters with observed seismicity and correlation among parameters could be considered. Additional parameters, such as rainfall patterns could be included. Alternative spatial analysis techniques that consider actual (non-discrete) values, instead of values reclassified to a common scale, could be considered. Finally, the study could be repeated with a more detailed and updated seismic event catalogue, which exists, but is not yet available to the public.

\section{Acknowledgements}

We would like to acknowledge the following organizations and people who contributed to this investigation: the Council for Geoscience, Michelle Grobbelaar; the University of Witwatersrand; Digby Wells Environmental; Bradley Thornton; Fabian Francis, Hesma Cockrell; DRD Gold, Greg Ovens; Prof. Chris Roth; GeoTerraImage; City of Johannesburg Corporate GIS, Deena Naidoo, Marcelle Hattingh; Eskom, Adri de le Rey, S'lindi Mhlongo. ArcGIS 10.1 was used in this investigation. 


\section{References}

Birch DJ 2013, Identifying Instability in the Rock Mass Caused by Water Ingress into Abandoned Mines. MSc Physics Dissertation, University of Pretoria, South Africa.

Bos M 1994, Drainage principles and applications, 1st Edition, Wageningen, Netherlands.

Cappa F 2009, Modelling fluid transfer and slip in a fault zone when integrating heterogeneous hydromechanical characteristics in its internal structure. Geophysical Journal International, 178, pp 1357-1362.

Coetzee H, Hobbs PJ, Burgess JE, Thomas A, Keet M 2010, Mine water management in the Witwatersrand goldfields with special reference to acid mine drainage, Report to the inter-ministerial committee on acid mine drainage, Pretoria. Prepared for: Water Research Commission: Report no. 486/1/95, Water Research Commission, Pretoria, South Africa, pp 237.

Davies N and Kijko A 2003, 'Seismic risk assessment: with an application to the South African insurance industry', South African Actuarial Journal, 3(1), pp. 1-28.

Durrheim RJ, Anderson, RL, Cichowicz, A, Ebrahim-Trollope, R, Hubert, G, Kijko, A, McGarr, A, Ortlepp WD, van der Merwe N 2006, Investigation into the risks to miners, mines, and the public associated with large seismic events in gold mining districts, CSIR, Pretoria, South Africa.

Esterhuyse S, Avenant M, Watson M, Redelinghuys N, Kijko A, Glazewski J, Plit LA, Kemp M, Smit A, Sokolic F, Vos AT, Reynolds D, Von Maltitz M, Van Tol J, Bragg C, Van Soelen B and Ouzman S 2014, Development of an interactive vulnerability map and monitoring framework to assess the potential environmental impact of unconventional oil and gas extraction by means of hydraulic fracturing. WRC Report No. 2149/1/14. ISBN 9781431205899.

Fenton CH, Adams J, Halchuk S 2006, Seismic hazards assessment for radioactive waste disposal sites in regions of low seismic activity. Geotechnical \& Geological Engineering, 24(3), pp 579-592.

Gibowicz SJ and Kijko A 1994, An Introduction to Mining Seismology, 1st edition, Academic Press, San Diego.

Goldbach O 2010, 'What is the Seismic Risk of Mine Flooding?' Science Real and Relevant Conference 2010, CSIR, Pretoria, South Africa.

Gough D 1970, Load induced earthquakes at Lake Kariba, Geophysics Journal, 21, pp 65-78.

Kijko A, Smit A, van de Coolwijk N and Kilian Z 2012, 'Methodology for probable maximum loss calculation and potential implications of acid mine water for the South African general insurance industry' Presentation at Actuarial Society 2012 Convention, 16-17 October 2012, Cape Town, South Africa.

Lay T and Wallace TC 1995, Modern Global Seismology, Volume 58 (International Geophysics), First Edition, Academic Press, San Diego.

Mualchin L 2011, 'History of Modern Earthquake Hazard Mapping and Assessment in California Using a Deterministic or Scenario Approach', Pure and Applied Geophysics, 168(3-4), pp. 383-407.

Servi M 2004, Assessment of vulnerability to Earthquake Hazards using Spatial Multicriteria Analysis: Odunpazari, Eskisehir Case Study, MSc dissertation in Geodetic and Geographic Information Technologies, Middle East Technical University, Ankara, Turkey.

Sieberg, A. (1923). "Erdbebenkunde", Jena, Ficher, August), modified and condensed; Quoted from Wood, H.O., and Neumann, F., (1931). "Modified Mercalli Intensity Scale of 1931", Bulletin of the Seismological Society of America, Vol. 21, No. 4, pp. 277283.

Simpson DW, Leith WS and Scholz CH 1988, Two Types of Reservoir- Induced Seismicity, Bulletin of the Seismological Society of America, 78 (6), pp 2025- 2040.

Talwani, P 1997, On the Nature of Reservoir-induced Seismicity, Pure appl. Geophys, 150, 473-492.

van Westen CJ 2013, 'Remote Sensing and GIS for Natural Hazards Assessment and Disaster Risk Management' in Schroder JF and Bishop MP Treatise on Geomorphology Academic Press, Elsevier, San Diego, pp. 259-298.

Wood, H.O., Neumann, F. (1931). Modified Mercalli Intensity Scale of 1931, Bulletin of the Seismological Society of America 21: 277-283.

Yuan Z 2003, Development of a GIS Interface for Seismic Hazard Assessment, MSc dissertation in Earth Resources and Environmental Geoscienes, International Institute for Geo-Information Science and Earth Observation, Enschede, the Netherlands. 